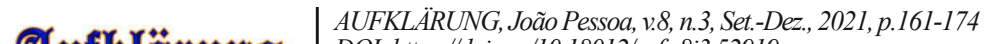 \\ Auffllärungr \\ Licença: Creative Commons 4.0 International (CC BY 4.0)
}

\section{JUSTIÇA COMO VIRTUDE ARTIFICIAL: SOBRE O ARTIFÍCIO HUMANO NA CONCEPÇÃO DE JUSTIÇA DE HUME}

[JUSTICE AS ARTIFICIAL VIRTUE: ON THE HUMAN ARTIFICE ON HUME'S CONCEPTION OF JUSTICE]

Gehad Marcon Bark * Universidade Federal do Paraná, Brasil

\begin{abstract}
Resumo: O artigo considera a tese humiana segundo qual a justiça é uma virtude artificial. Com base na análise de alguma das concepções apresentadas nas obras Tratado da Natureza Humana e Investigação sobre os Princípios da Moral, este texto propõe que a afirmação em questão exige uma qualificação. A noção de artifício, no contexto da discussão sobre justiça, deve ser compreendida à luz de uma relação fundamental entre disposições da espécie humana: a reflexão na sua atividade de refrear as paixões. Nesse sentido, o artificial, enquanto relacionado a isso que se concebe como artifício humano, pode ser compreendido, de alguma maneira, como natural, enquanto caracteristico da espécie humana.
\end{abstract}

Palavras-chave: Artifício; Hume; justiça; natureza humana; virtudes artificiais
ABstract: The paper considers the humean thesis according to which the justice is an artificial virtue. Based on the analysis of some of the conceptions presented in A Treatise of Human Nature and An Enquiry Concerning the Principles of Morals, this text proposes that the considered statement requires a qualification. The notion of artifice, in the context of the discussion about justice, should be understood in the light of one fundamental relation between dispositions of the human species: the reflection in the activity of refraining passions. In this sense, the artificial, as related to what is taken to be the human artifice, can be understood, somehow, as natural, while specific to the human species.

KEYwORDS: Artifice; Hume; justice; human nature; artificial virtues

\section{INTRODUÇÃo}

presente artigo é dedicado a uma reflexão sobre o sentido em que se deve Essa afirmação, que introduz uma distinção medular, na obra de Hume, entre virtudes naturais e artificiais, é objeto tanto da discussão inaugural desenvolvida na Parte 2 do Livro 3 do Tratado da Natureza Humana, quanto daquela que é desenvolvida especialmente no Apêndice 3 da Investigação sobre os Princípios da Morall. A proposta do texto, em linhas gerais, é argumentar que, na distinção em questão, a despeito de afirmações fortes sustentadas por Hume que parecem subsidiar uma compreensão diversa $^{2}$, a justiça é dita artificial unicamente por ter sua origem em uma capacidade de reflexão que leva em conta a utilidade de um concerto de vontades para o alcance de um propósito - segundo a conhecida metáfora dos remadores ${ }^{3}$. Enquanto fruto de um artificio eminentemente humano, a justiça não deixa de ser natural em um certo sentido, a dizer, na medida em que pode ser encarada como "obra da razão"4, como produto final

* Doutorando pelo Programa de Pós-Graduação em Filosofia da Universidade Federal do Paraná.Email: gehad_marcon_bark@hotmail.com 
de um refinamento fundado no uso de uma faculdade humana, capaz de redirecionar o "movimento cego e impetuoso"s das paixões.

Dizendo de outro modo, propõe-se que a afirmação inicialmente considerada exige uma qualificação, sugerida em passagens significativas pelo próprio autor. Para Hume, a justiça encontra o seu fundamento em uma disposição igualmente ínsita à natureza humana, mas que difere daquela que origina, por exemplo, o sentimento humanitário - que está na base da virtude natural da benevolência. Nesse registro, o que pretendo sustentar é que a mobilização da distinção entre virtudes naturais e artificiais está intimamente relacionada, em última instância, à compreensão da relação fundamental que há entre disposições que repousam sobre a natureza humana e suas capacidades, ainda que algumas delas dependam da confluência de determinadas condições para serem atualizadas, como parece suceder com as regras de justiça.

A primeira seção reconstrói, no que é essencial, o tratamento que Hume confere à questão do surgimento das regras de justiça (às quais se atribui, então, isso que se concebe como um caráter artificial). A segunda parte do texto explora, a partir de passagens do Tratado da Natureza Humana, da Investigação sobre os Princípios da Moral e, adicionalmente, do Ensaio sobre a origem do governo, uma compreensão possível disso que o filósofo concebe como um artifício engendrado pela espécie humana.

\section{HuME E A GÊNESE DAS REGRAS DE JUSTIÇA}

Uma boa maneira de apresentar o problema indicado na introdução é partir de uma brevíssima reconstrução da questão que Hume considera na Seção 1 da Parte 2 do Livro 3 do Tratado da Natureza Humana, cujo título nada mais é do que a formulação da seguinte pergunta: "Justiça, uma virtude natural ou artificial?"6. A literatura secundária deu à discussão que introduz a reflexão humiana sobre a origem da justiça o nome de questão do "círculo da justiça". Para restringir a questão ao fundamental, o ponto é que, diferentemente do que ocorre com as virtudes naturais, no caso da virtude da justiça, aparentemente não encontramos um motivo virtuoso, original, com base no qual possamos justificar que consideremos determinadas ações como justas. Hume observa que um pai que deixa de prestar os cuidados aos seus filhos é censurado por demonstrar, no seu modo de agir, uma carência de afeição natural no trato com a sua prole. De igual modo, uma pessoa extremamente benevolente é louvada em razão do sentimento humanitário que o impele à prática de ações caridosas. Em ambos os casos, afeição natural e sentimento humanitário são motivos virtuosos. O mérito ou demérito das ações externas é avaliado à luz desses motivos anteriores, distintos da consideração pela virtude da ação. É sobre esse motivo natural que formulamos juizos de aprovação ou reprovação das ações - ações que, observa Hume, são "signos" quais visamos justamente o motivo último que é objeto de avaliação.

As coisas parecem ocorrer de outro modo, todavia, quando tratamos da virtude da justiça. Aparentemente não há nenhum motivo natural na base de nossa estima por atos considerados justos. Um sentimento de "honestidade e justiça", recorrentemente tratado por Hume, por sinal, como acessível apenas em estágios mais avançados da sociedade, é de pronto recusado por ser inapreensível para seres que se encontram em uma condição mais primitiva da humanidade. Mas tampouco a consideração pela própria honestidade da ação (como sugere o exemplo do indivíduo que considera as razões que o levariam a devolver o dinheiro tomado de empréstimo) pode ser a fonte da aprovação da conduta. Nesse último caso - e aqui se evidencia a circularidade 
denunciada por Hume -, seria ilícito buscar na própria consideração pela honestidade da ação o motivo pelo qual tomamos a ação como honesta. Dependemos de um motivo virtuoso que seja anterior e distinto da consideração pela justiça da ação, mas que, ao contrário do que ocorre com outras virtudes, não conseguimos encontrar.

Nem mesmo o amor por si próprio (sob o enfoque do interesse privado e da reputação pessoal), o respeito pelo interesse público, o amor pela humanidade, ou o respeito pelos interesses de terceiros, constituem motivos virtuosos distintos da consideração pela honestidade da ação. O primeiro é insuficiente não apenas porque na sua ausência não haveria espaço para ações honestas, mas porque interesses dessa espécie, quando perseguidos de forma incontida, são causa de inúmeras injustiças (exigindo, como antecipa Hume, alguma espécie de limitação em face do seu "movimento natural" 10 ). Quanto ao interesse público, o principal motivo para sua recusa parece consistir no seu "caráter demasiadamente remoto e sublime"11, especialmente quando contrastado, mais uma vez, com interesses de ordem privada, que parecem predominar em estágios mais primitivos da sociedade. Em relação ao amor pela humanidade, Hume expressa uma posição claramente cética, afirma que nenhum "fenômeno aponta para a existência dessa terna afeição pelos homens, independentemente de seu mérito ou de qualquer outra circunstância"12. Por fim, ao considerarmos o respeito pelos interesses dos outros como um possivel motivo original, temos de dar conta da multiplicidade de relações interpessoais que, ligadas a circunstâncias essencialmente contingentes, tornaria impossível a instituição de regras estáveis para regulação das relações sociais.

Sem a pretensão de perscrutar no detalhe os argumentos mobilizados nessa etapa do argumento, vê-se com muita clareza que, para cada um dos possíveis candidatos sugeridos, o filósofo oferece razões para concluir que, ao fim e ao cabo, "não temos naturalmente nenhum motivo real ou universal para observar as leis de equidade, exceto a própria equidade e o mérito dessa observância"13. Como a equidade e o mérito da observância não são fundamentos distintos da consideração pela honestidade da ação, incorremos em um raciocínio circular que não poderemos dissolver, prossegue Hume, a menos que admitamos que "o sentido de justiça e injustiça não deriva da natureza, surgindo antes artificialmente, embora necessariamente, da educação e das convenções humanas"14.

É instrutivo considerar essa espécie de gênese da justiça - ou, mais propriamente, dos rudimentos daquelas que serão numa sociedade plenamente desenvolvida as regras de justiça - que Hume persegue na Seção 2. Essa questão ${ }^{15}$, que ocupa a maior parte da reflexão de Hume nesse momento, está ligada, nas palavras de Kenneth R. Westphal, a "problemas de coordenação social" que levam à instituição de regras de justiça ${ }^{17}$. Dos cinco problemas que Westphal considera em sua reconstrução do pensamento humiano, o primeiro deles é que nos interessa mais imediatamente. O ponto central é que, dada uma conjunção de fatores, as denominadas "circunstâncias da justiça"18, somos conduzidos à vida em sociedade pelas vantagens que, a longo prazo, extraímos da coordenação de nossas ações.

Somos seres com uma disposição natural para cultivar o amor próprio e a afeição pelos indivíduos mais próximos a nós em detrimento de terceiros. Essa propensão é causa de "uma oposição de paixões, e consequentemente, uma oposição de ações"19, certamente perniciosa para o convívio social, mas "pouco perigosa" 20 por si mesma. $\mathrm{O}$ fator determinante para a necessidade de uma regulação está ligado à "fruição dos bens que adquirimos com nosso trabalho e nossa boa sorte" 21 : não apenas os bens externos são escassos na natureza, como sua posse pode ser transferida de uma pessoa para outro com muita facilidade - inclusive e, talvez mais frequentemente, pelo uso da violência. 
Como a natureza não nos brindou com o equilíbrio entre as necessidades e os instrumentos para satisfação dessas necessidades individualmente (como fez com outros animais não humanos), uma convenção é requerida para assegurar a estabilidade dessa posse que, de outro modo, está submetida a constantes violações por indivíduos naturalmente movidos por seus interesses parciais.

Embora pouco perigosas se desacompanhadas das intempéries ligadas ao livre gozo dos bens externos, as paixões desempenham um importante papel na argumentação de Hume. O ponto de partida de Hume é um estado primitivo em que o sentimento sobre o justo é, ainda, inacessível. E a causa dessa espécie de incompreensão, segundo o filósofo escocês, está na "estrutura original de nossa mente"22, que dispensa o maior grau de atenção a nós mesmos, um pouco menos de atenção aos parentes e amigos e, finalmente, o menor grau aos estranhos. Isso reaparece, mais adiante, em uma observação com relação das duas qualidades da mente humana: "egoísmo" e "generosidade restrita" 23 . Somos parciais (egoístas e generosos com nossos parentes e amigos) e a tal ponto movidos por nossas paixões, que mesmo nossos sentimentos sobre a moral, sobre como devemos nos portar, são fortemente influenciados. Em um estado primitivo mesmo as ideias que formamos acerca da moral tendem a resultar de uma intensificação da parcialidade originária dos afetos. Hume propõe que essa parcialidade está na base de "regras comuns do dever, que nos fazem preferir uns aos outros"24. Para Hume - e essa tese é tratada como um corolário das conclusões extraídas na Seção 1 -, se toda avaliação moral está fundada em um motivo virtuoso ligado a certas paixões, então as paixões devem influenciar nossos juízos sobre a correção ou incorreção de nossas ações.

É no contexto dessa observação sobre as qualidades da mente humana, descrita como egoísta e generosa de maneira restrita (em meio à escassez de bens e à instabilidade da posse), que Hume propõe que uma espécie de correção, ou, ainda, um remédio, "não vem da natureza, mas do artifício" 25 . A solução oferecida, qual seja, "uma convenção, de que participam todos os membros da sociedade, para dar estabilidade à posse desses bens externos" ${ }^{26}$, reafirma uma tese anunciada já na Seção 1. Para seres como nós, movidos por paixões e afetos que nos tornam naturalmente parciais, o sentido de justiça e injustiça é fundado em um interesse privado pela preservação da posse de bens externos. No mesmo registro dessas observações, outros trechos da Seção 2 contêm afirmações igualmente fortes a respeito do caráter artificial da virtude da justiça. Hume afirma que:

É absurdo, portanto, imaginar que podemos ter uma ideia de propriedade sem compreender completamente a natureza da justiça e mostrar sua origem no artifício e na invenção humana. A origem da justiça explica a da propriedade. Ambas são geradas pelo mesmo artifício. Como nosso primeiro e mais natural sentimento moral está fundado na natureza de nossas paixões, e dá preferência a nós e a nossos amigos sobre estranhos, é impossivel que exista naturalmente algo como um direito ou uma propriedade estabelecida, enquanto as paixões opostas dos homens os impelem em direções contrárias e não são restringidas por nenhuma convenção ou acordo. ${ }^{27}$

Em uma das conclusões extraídas a partir da análise da questão da gênese da justiça, Hume sustenta, justamente, que "as impressões que dão origem a esse sentido de justiça não são naturais à mente do homem, surgindo antes do artificio e das convenções humanas"28. É significativo que o filósofo considere conhecidas imagens literárias do período, que retratam uma suposta época de abundância e benevolência humana, para afirmar que nessas situações fictícias - compreensíveis a partir de exemplos extraídos da experiência ${ }^{29}$ - regras de justiça não teriam qualquer utilidade. 
À luz de afirmações tão explícitas, é difícil sugerir como a instituição de regras de justiça não seria uma espécie de movimento ou resposta para circunstâncias específicas em que vivemos, meramente circunstancial, mas em todo caso fundamentalmente estranho às inclinações naturais que animam os seres humanos. Para colocar em termos mais claros, é difícil compreender como o surgimento dessas regras de justiça, em um estágio primitivo da sociedade, não seria fruto de um movimento contrário à própria natureza humana. Hume sustenta que isso ocorre, explicitamente em alguns momentos, como na passagem em que afirma que regras de justiça "são inventadas artificialmente com um certo propósito, sendo contrárias aos princípios comuns da natureza humana" 30 .

O primeiro passo para a compreensão da questão que se coloca é reconhecer que os textos de Hume exprimem, de forma inequívoca, uma tensão. Tensão que adquire contornos claros especialmente claros quando consideramos que, mesmo na passagem do Tratado para a exposição que é feita no texto da Investigação sobre os Princípios da Moral, a distinção entre virtudes naturais e artificiais não é completamente abandonada. $\mathrm{O}$ autor parece comprometido com uma tese mais forte não apenas pelo teor das afirmações acima consideradas, mas pela própria maneira de apresentar o argumento central do texto. Recordemos que o ponto de partida da análise é o problema do círculo da justiça: ao contrário do que ocorre com as virtudes naturais, não há um motivo natural na base das regras de justiça.

Pela reconstrução aqui sugerida, Hume sem dúvida reconhece na circunstância relativa à escassez de bens externos o motivo determinante para a instituição de regras para a estabilização da posse, mas também atribui papel relevante, nesse processo, à atuação de certas qualidades naturais da mente humana. Em meio aos conflitos causados por nossa parcialidade, é um interesse eminentemente privado que, ao fim e ao cabo, possibilita uma coordenação de ações para a garantia da posse. A questão, aqui, consiste em que, pelo modo como essa convenção é descrita, a partir de seu caráter artificial, nas formulações textuais acima consideradas, o leitor pode ser levado a crer que Hume pensa o artificial como sendo o contrário, de alguma maneira, em relação ao que é característico da natureza humana.

Contudo, se por um lado temos de conceder esse primeiro ponto, por outro é preciso enfatizar que as reflexões de Hume são explicitamente permeadas por uma preocupação muito pontual com uma qualificação de algumas afirmações a respeito do caráter artificial da virtude da justiça. Esse detalhe crucial não pode ser negligenciado e parece indicar elementos para que rejeitemos uma leitura que vê na tese sobre o caráter artificial da virtude da justiça uma espécie de oposição ao que poderia ser encarado como natural enquanto produto de uma disposição característica da espécie humana. Nesse sentido é que se propõe como fundamental uma adequada compreensão da relação entre capacidades ou disposições que está na base do surgimento das regras de justiça.

\section{A NATUREZA DO ARTIFÍCIO HUMANO}

No último parágrafo da Seção 1, Hume faz um claro alerta a seus leitores: "quando nego que a justiça seja uma virtude natural, estou empregando a palavra natural como significando exclusivamente o oposto de artificial" 31 . Isso nos autoriza a supor que há outros termos em relação aos quais a palavra "natural" também pode ser contraposta e segundo os quais a própria virtude da justiça poderia ser encarada como natural. E a suposição é confirmada pelo encaminhamento do texto. Hume afirma que, a depender 
do sentido da palavra, "nenhuma virtude é mais natural que a justiça"32. O autor retoma nesse ponto, claramente, distinções consideradas já na Seção 2 da Parte 1 do Livro 3. O termo "natural" (e mesmo a palavra "natureza") pode ser oposto tanto ao que é considerado milagroso, quanto ao que é "raro e inabitual" 33 . Mas a natureza pode ser oposta, igualmente, a artificio, e é no detalhe que perpassa essa distinção em particular, evidentemente, que há um importante aspecto a ser considerado.

É que artifício e natureza se distinguem contanto que se compreenda que "os desígnios, projetos e objetivos dos homens são princípios tão necessários em sua operação quanto o calor e o frio, o úmido e o seco" 34 . É bem verdade que essa última observação introduz a própria distinção entre virtudes naturais e artificiais. Contudo, quando o problema é retomado na Seção 1 da Parte 2, logo depois de afirmar que não há virtude mais natural que a justiça, Hume faz uma afirmação bastante esclarecedora:

O homem é uma espécie inventiva; e quando uma invenção é evidente e absolutamente necessária, é tão correto considerá-la natural quanto que proceda imediatamente de princípios naturais, sem a intervenção do pensamento ou reflexão. Embora as regras da justiça sejam artificiais, não são arbitrárias. Tampouco é impróprio utilizar a expressão Leis Naturais ["Laws of Nature"] para caracterizá-las, se entendermos por natural aquilo que é comum a uma espécie qualquer, ou mesmo se restringirmos seu sentido apenas ao que é inseparável dessa espécie. ${ }^{35}$

$\mathrm{Na}$ Seção 2, observamos que Hume, bastante cauteloso, propõe uma reformulação que caminha no mesmo sentido. Não se trata propriamente de afirmar que o remédio não vem da natureza, mas de compreender que "a natureza fornece, no juizo e no entendimento, um remédio para o que há de irregular e inconveniente nos afetos" 36 . Evidencia-se nos dois trechos um claro movimento em direção à compreensão das afirmações segundo um sentido em que a justiça pode ser encarada como natural não apenas enquanto oposta ao milagroso, ao raro ou incomum, mas enquanto produto de uma capacidade inerente a essa natureza inventiva dos seres humanos. Conjugadas às afirmações que Hume sustenta na Investigação sobre os Princípios da Moral e no Ensaio sobre a origem do Governo, essas passagens parecem decisivas.

No Apêndice 3 da Investigação, Hume dedica parte de sua reflexão à tarefa de elucidar o que é característico da convenção humana que dá origem à justiça. Para Stephen Buckle, é possível evidenciar, na última obra, uma mudança sútil no enfoque da discussão cujo intuito seria desfazer controvérsias que a ênfase no caráter artificial da justiça, presente no Tratado, suscitou entre outros autores da época ${ }^{37}$. Segundo o intérprete, exemplo desse remanejamento terminológico estaria presente no fato de que o termo "artificial" é mencionado apenas em uma nota de rodapé ao longo do texto ${ }^{38}$. Com efeito, embora a mesma posição com respeito à possibilidade de oposição entre natureza, milagre e artifício, presente no Tratado, esteja sendo reafirmada, observamos claramente uma tentativa de aproximar a virtude da justiça de algo naturalmente ínsito à espécie humana.

Nesse ponto, é especialmente significativo o tratamento conferido ao termo "natural". Conquanto vaga e ambígua segundo Hume ${ }^{39}$, a palavra empregada pode ser aplicada tanto para caracterizar amor por si mesmo e a benevolência (motivos originais que estão na base do sentido de dever de virtudes naturais), quanto para as virtudes da "justiça, ordem, fidelidade, propriedade, sociedade" 40 . E a razão para isso é que, tanto quanto as paixões e os afetos, "a razão e a prudência"41 são, sem mais, naturais à espécie humana. $\mathrm{Na}$ esteira da análise desenvolvida a partir das limitações que engendram problemas de coordenação social, "paixões e reflexões" 42 , que reconhecemos entre nossos pares, conduzem à instituição de regras de justiça. Presumidamente a partir da 
confluência entre o produto dessas duas capacidades, esse "sentimento de justiça", prossegue Hume, "manifestou-se de maneira certa e infalível, em maior ou menor grau, em todo indivíduo da espécie humana"43. E, na medida em que a virtude da justiça "surge necessariamente do exercício de suas faculdades intelectuais", nesse "animal tão sagaz"44, podemos tratá-la como natural.

São igualmente sugestivas algumas afirmações feitas no Ensaio sobre a origem do governo. Nesse opúsculo, Hume trata da relação entre autoridade e obediência e apresenta sua famosa tese sobre "a luta intestina perpétua, aberta ou secreta, entre autoridade e liberdade [liberty]" 45 , existente em todo governo. Logo na passagem que inaugura o texto, entretanto, o autor diz que o "ser humano, nascido em família, é compelido a manter sociedade por necessidade, por inclinação natural e por hábito"46. $\mathrm{Na}$ sequência, lemos que a "mesma criatura, em seu progresso posterior [further], está engajada em estabelecer uma sociedade politica a fim de administrar a justiça, sem a qual não pode haver paz (...)."47 Mas é a qualificação da justiça como um "dever primitivo e natural" 48 que pode causar surpresa, especialmente se rememorarmos a maneira pela qual o tema é originalmente introduzido no Tratado, a dizer, a partir da problemática do ć́rculo da justiça, que afirma que não há um motivo natural que corresponda ao sentimento de justiça. A terminologia utilizada nos dois textos é, inclusive, bastante próxima: no Tratado encontramos afirmações sobre aquilo que define o sentimento de dever em relação a uma virtude natural - um motivo natural que, segundo a primeira obra, não encontramos quando voltamos os olhos para a justiça; no Ensaio nos deparamos com uma formulação aparentemente oposta a respeito da origem, primitiva e igualmente natural, do dever de justiça.

Proponho que os três textos acima considerados, ao tempo em que explicitam a tensão mencionada no final da seção anterior, oferecem elementos para que pensemos em uma noção "naturalizada" de artifício e, por conseguinte, da virtude da justiça. Com amparo nessas passagens, a chave de leitura aqui esboçada aposta na distinção entre o natural e o artificial enquanto articulada unicamente sobre o exercício de faculdades distintas, porém intrínsecas à espécie humana. Não estou me distanciando, nessa incursão, da interpretação de Stephen Buckle, nem tampouco da leitura de Kenneth R. Westphal. Apenas para ilustrar o ponto, Westphal é bastante explícito quando, na tentativa de aclarar a importante distinção entre artificio e arbitrariedade, sustenta que Hume é herdeiro de uma tradição que vincula a agência prática "à natureza humana e [sua] atividade" 49 .

É oportuno insistir nessa abordagem, mas uma pequena mudança na perspectiva de análise pode auxiliar na compreensão do ponto. Ao invés de focarmos a oposição entre artifício e arbitrariedade, consideremos a atividade das paixões e da reflexão em sua relação com o que há de necessário quando tratamos da justiça como uma virtude artificial. Nesse ponto, a análise de Buckle é bastante oportuna. Muito esquematicamente, fiel à tarefa de propor uma reconstrução do pensamento de Hume segundo a doutrina da lei natural ${ }^{50}$, o intérprete propõe que uma reflexão, a partir da capacidade racional da espécie humana, precede a instituição de regras de justiça ${ }^{51}$. Gradativamente, os indivíduos tomam consciência dos riscos existentes em uma situação de absoluta licenciosidade e refletem sobre as vantagens advindas da organização de regras em torno da propriedade. O essencial é que, conquanto essas regras não sejam "fruto de um instinto original da natureza humana", sem a sua instituição "a sociedade humana não pode prosperar" 52 . Na medida em que responde pela "utilidade racional"53 da vida em sociedade, necessária para o desenvolvimento da espécie humana, a instituição dessas regras pode ser tomada como fruto de uma lei natural. Segundo Buckle, as regras em torno da posse e da propriedade, "surgindo [...] do trabalho natural 
da mente humana, surgem necessariamente e, por conseguinte, naturalmente" ${ }^{54}$. Em outras palavras, recuperando uma vez mais um dos aspectos essenciais da leitura de Westphal, essas regras são "'Leis da Natureza' porque para seres humanos são totalmente indispensáveis e, assim, não opcionais e não arbitrárias" 55 .

Embora sejamos movidos por nossas paixões e afetos, somos igualmente capazes

168 de reflexão, e, mais do que isso, exatamente por sermos parciais, dadas as circunstâncias externas, somos impelidos a refletir sobre as vantagens de um arranjo que assegure a estabilidade da posse dos bens. Quando refletimos sobre questões de coordenação social, Hume parece sugerir que, a depender das circunstâncias com as quais venhamos a nos deparar, necessariamente somos levados a fazê-lo, tanto quanto um leão cuja voracidade é compensada pelas habilidades de caça, ou um carneiro é dotado de um apetite moderado. É esse jogo entre as paixões e a capacidade de reflexão, incontornável para indivíduos da espécie humana, que, em última instância, está na base da distinção entre o que é natural e o que é artificial.

É claro que ao menos alguma distinção entre dois domínios do natural, por assim dizer, está sendo mobilizada nessa análise. Há uma diferença entre aquilo que pertence à natureza na forma de um interesse parcial originário na satisfação de desejos sensíveis, e o que é próprio da natureza humana, enquanto dotada de uma faculdade específica para a reflexão que, dadas certas condições, atua ao lado das paixões como uma forma de limitação. Como recorda Westphal, o que aqui se denomina de "caráter natural ["naturalness"]" é natural enquanto "diz respeito à natureza humana"56. Bem compreendido esse ponto, parece não haver problema em sustentar que o artifício pode ser encarado, em alguma medida, como natural. Parece igualmente razoável admitir que não há propriamente uma oposição fundamental entre as noções expressas pelos predicados "natural" e "artificial" utilizados para caracterizar as virtudes, mas distintos domínios do que pode ser encarado como natural em um sentido mais amplo que designa aquilo que é comum à espécie ou inseparável dela. $\mathrm{O}$ artificial é natural enquanto pertencente à natureza humana, isto é, na medida em que designa a capacidade humana, necessária em certos contextos, de agir por artifícios - artifício que engendra regras de justiça e que, recorda Hume, "manifestou-se de maneira certa e infalível (...) em todo individuo da espécie humana" 57.

Se há algum sentido de necessidade envolvido no artifício humano (necessário enquanto não arbitrário), não parece inadequado encontrar suporte para a leitura sugerida na relação mais geral que Hume pretende estabelecer entre a noção de necessidade e a tarefa de compreender a ação humana. Para Hume, é um princípio básico "que, ao julgar as ações humanas, devemos proceder com base nas mesmas máximas que quando raciocinamos acerca dos objetos externos" 58 . Essa afirmação surge no mesmo contexto em que Hume faz clara alusão à necessidade de se "admitir que a sociedade humana se funda em princípios semelhantes" 59 àqueles que regulam nossa compreensão sobre as relações de causa e efeito nos objetos. É assim que não apenas observamos, na experiência, "que os homens sempre buscam a sociedade, mas [que], além disso, podemos explicar os princípios em que se funda essa propensão universal" 60 . Instruídos por essas afirmações e pelo projeto geral de "marchar diretamente para a capital (...), para a própria natureza humana" 61 a fim de compreender "lógica, moral, critica e política" 62 , é razoável concluir que investigação sobre a gênese da justiça é, ao fim e ao cabo, uma investigação sobre a origem de um artifício que está ancorado em uma relação fundamental entre as paixões e a capacidade de reflexão. Em termos mais gerais, aliás, essa mesma relação é essencial para a própria compreensão da ação humana, que Hume muito claramente sustenta não resultar unicamente do emprego da faculdade da razão ${ }^{63}$. Embora não seja capaz de produzir, por si só, uma ação, a reflexão 
possui um papel determinante na recondução do "movimento cego e impetuoso"64 das paixões. Em suma, o ponto central é que a própria ação humana - e aquilo que é característico da natureza humana e suas ações inclusive sob a forma do artifício - não pode ser dissociada dessa relação fundamental, e em todo caso absolutamente natural à espécie humana, que se dá entre as paixões e a reflexão.

Evidentemente, essa compreensão sobre o que há de natural no artifício humano precisa dar conta de um problema mais imediato. Nesse ponto, é necessário recordar que Hume é bastante claro quando afirma que, mais do que resultar meramente da nossa parcialidade, a instituição de regras de justiça é a tal ponto indissociável de problemas relacionadas à fruição de bens externos, que não as conheceríamos se estivéssemos sob outras circunstâncias (nomeadamente, uma situação de abundância de bens externos). Se o argumento for levado às últimas consequências, temos de assumir que, nessa situação contrafactual que Hume explicitamente considera em sua análise ${ }^{65}$, regras de justiça não surgiriam: nossa parcialidade seria integralmente satisfeita pelos bens externos já disponíveis e as relações seriam conduzidas em uma direção completamente distinta. Numa situação hipotética de duradoura abundância, uma convenção em torno de regras de justiça não teria lugar justamente por não ser útil - e a utilidade, vale recordar, inaugura a reflexão humiana sobre a justiça no texto da Investigação sobre os Princípios da Moral ${ }^{66}$. É difícil compreender, nesse registro, como as regras de justiça, sendo artificiais, não teriam de ser tomadas, em sentido forte, como contrárias à natureza humana - como Hume propõe explicitamente, por sinal, em passagem já anteriormente citada $^{67}$. É quase como se a vocação natural da espécie humana fosse diversa. Seríamos "naturalmente benévolos, pois não haveria conflitos, uma vez que todos, sem exceção, estariam absolutamente satisfeitos" ${ }^{\prime \prime 8}$.

Uma resposta possível para o problema posto reside no seguinte: ainda que possamos pensar em uma situação contrafactual de extrema abundância, necessariamente, se sucede que nossa parcialidade é confrontada com a escassez de bens e a instabilidade da posse, regras de justiça são instituídas a partir do jogo entre as paixões e a reflexão racional. Regras de justiça seriam instituídas a partir de uma atualização de disposições humanas para a reflexão. Reflexão a partir da qual engendramos certos artifícios para dar conta de problemas que surgem em decorrência do convívio social. Nesse sentido, podemos tratar como uma circunstância contingente que os bens externos sejam escassos e que sua posse seja instável, mas, necessariamente, se bens externos são escassos e sua posse é instável, então regras de justiça, fruto de um artificio humano, são instituidas para regular as relações sociais. Compreendendo-se que não há alternativa para o desenvolvimento da espécie humana dadas as circunstâncias vigentes - e Hume é igualmente explícito ao assumir esse ponto de vista -, não há razões para recusar que essa afirmação seja apta a expressar uma regra geral ligada à natureza humana.

Essa interpretação parece encontrar apoio textual em outra passagem contida ao final do Ensaio sobre a origem do governo. Nesse texto, depois de reafirmar a recorrentemente afirmada relação entre a justiça e "princípios óbvios da natureza humana"69 (para a formação de uma aliança), Hume diz que esse "progresso dos assuntos humanos [human affairs]" não pode ser "descoberto de antemão", nem sua "operação antevista" " . O governo, diz o autor, "começa mais casualmente e de forma imperfeita" "71 mais provavelmente como fruto de uma situação de conflito persistente em que "os efeitos perniciosos da desordem são sentidos de forma mais sensível" 72 . Nesse contexto, a ascendência de um indivíduo com autoridade encontra como uma de suas causas a premência de um acordo entre sujeitos parciais ${ }^{73}$. Para além das dimensões do conflito potencial e da convenção que perpassam toda a reflexão de Hume, vemos 
esboçada uma nova afirmação sobre o fundamento dúplice da instituição de regras de convívio social como um artifício: disposições naturais comuns à espécie que, ainda assim, carecem de contextos específicos para serem plenamente desenvolvidas (sob pena de, do contrário, não serem atualizadas).

Poderíamos traçar, ainda, um paralelo entre essa leitura e, mais 170 contemporaneamente, a proposta de Otfried Höffe de pensar uma legitimação pragmática da coerção estatal, numa sociedade de indivíduos egoístas (isto é, indivíduos centrados apenas em seus próprios interesses individuais), a partir do modelo "antropologia mais ética"74. Mutatis mutandis, interessa-nos especificamente a dimensão contida na premissa antropológica da justificação ensaiada pelo autor: "a coexistência [de indivíduos] no mesmo mundo externo"75. O essencial a preservar dessa reflexão é que a tarefa de pensar os fundamentos de uma regulação social a partir de regras (do ponto de vista de sua legitimação, ou, como ocorre no primeiro passo do argumento de Hume considerado nesse artigo ${ }^{76}$, do ponto de vista de sua gênese) supõe um conjunto de dados empíricos sobre a condição humana e o sobre o mundo. Höffe propõe uma redução, segundo o espírito kantiano, a um conjunto mínimo de dados antropológicos (a coexistência de indivíduos no mesmo espaço físico) $)^{77}$, ao passo que Hume desenvolve sua análise, claramente, a partir de um conjunto mais amplo de pressupostos dessa ordem: a parcialidade de cada ser humano em um contexto de escassez relativa e de instabilidade da posse bens externos.

Em Hume, é a partir desse conjunto de dados empíricos que a relação entre paixão e reflexão atualiza disposições naturalmente ligadas às capacidades humanas. $\mathrm{O}$ artifício, considerando aquilo que as circunstâncias demandam caso queiramos satisfazer nossos interesses privados, acaba por se tornar um expediente necessário do qual a espécie (humana) naturalmente lança mão. É melhor um pacto, do que um estado permanente de conflitos potenciais. Mas poderia ser o caso que as circunstâncias fossem outras. Nessa situação, as disposições para a concepção de artifícios, ainda que naturais, não encontrariam espaço para o seu desenvolvimento. Feita essa ressalva, é possível compatibilizar o tratamento conferido ao artifício humano como natural com a concepção humiana segundo a qual uma situação de abundância de bens externos dispensaria regras dessa espécie.

Deve ficar claro que essa leitura dos textos de Hume sugere que, necessariamente, dado o concurso entre nossas paixões e a limitação de bens externos, alguma convenção em torno de regras para a estabilização da posse deve surgir. É certo que as circunstâncias específicas das diversas convenções obedecem a particularidades e contingências históricas que, invariavelmente, perpassaram a constituição de cada agrupamento social. No entanto - e o ponto fundamental da relação entre o necessário e o natural é esse -, que haja uma convenção nas circunstâncias já descritas, enquanto o produto da capacidade para a reflexão que limita as paixões, é algo necessário para o desenvolvimento da espécie humana. Dá o caráter natural do artifício pelo qual as regras de justiça são instituídas.

\section{CONSIDERaÇões FINAIS}

Conduzidos pela reconstrução proposta ao longo do presente texto, poderíamos, finalmente, formular a seguinte pergunta: qual é a razão pela qual Hume insiste na distinção entre natural e artificial ao tratar da origem da virtude da justiça? $\mathrm{Ou}$, ainda, em que medida a artificialidade da justiça importa a Hume? Afinal de contas, se é certo que os textos considerados evidenciam um movimento na direção da qualificação das 
afirmações sobre o caráter artificial da justiça, é inequívoco que o filósofo não abdica dessa nomenclatura que é introduzida pela vez primeira ainda no corpo do Tratado. Mesmo no Ensaio sobre a origem do governo, vemos que a distinção perpassa, ainda que indiretamente, a discussão sobre a origem do governo.

Uma resposta possível já foi sinalizada anteriormente: a distinção entre o artificial e o natural marca, justamente, a diferença entre o que pode ser tratado como uma disposição natural e originária da espécie humana ligada à satisfação das paixões que persiste, sejam quais forem as circunstâncias, e disposições que são igualmente comuns à espécie humana, mas dependem da concorrência de fatores externos para serem atualizadas. Em outras palavras, vivamos ou não em condições de escassez relativa de bens instabilidade de posse, desejamos e até mesmo necessitamos de objetos externos para nossa sobrevivência, ao passo que regras em torno da posse desses objetos somente surgem, ainda que por um movimento natural da espécie humana, apenas sob circunstâncias específicas.

\section{REFERÊNCIAS}

BUCKLE, Stephen. Natural law and the theory of property: Grotius to Hume. New York and Oxford: Oxford University Press, 1991.

CUNHA, Denise Carolina da; MACHADO, Nivaldo. 'Simpatia e aprovação moral da justiça na filosofia de Hume', in Jaimir Conte; Flávio Zimmermann; Marília Cortês de Ferraz (Org.). Ensaios sobre a filosofia de Hume. Florianópolis: NEL/UFSC, 2016, pp. 291-310.

HÖFFE, Otfried. 'Even a nation of demons needs the state': the dilemma of natural justice, in Howard Willians (Ed.). Essays on Kant's political philosophy. Cardif: University of Wales Press, 1992.

HUME, David. 'Of the origin of government', in Stephen Coplay; Andrew Edgar (Eds.). David Hume selected essays. Oxford: Oxford University Press, 1998.

HUME, David. Investigações sobre o entendimento humano e sobre os princípios da moral. Tradução de José Oscar de Almeida Marques. São Paulo: Unesp, 2004.

HUME, David. Tratado da Natureza Humana. Tradução de Déborah Danowski: 2. ed. São Paulo: Unesp, 2009.

KANT, Immanuel. Die Metaphysik der Sitten. Ditzingen: Reclam, 2016.

HUME, David. Princípios Metafísicos da Doutrina do Direito. Tradução de Joãosinho Beckenkamp. São Paulo: Martins Fontes, 2014.

LIMONGI, Maria Isabel. 'Hume e a Magna Carta: em torno do círculo da justiça', in Jaimir Conte; Flávio Zimmermann; Marilia Cortês de Ferraz (Org.). Ensaios sobre a filosofia de Hume. Florianópolis: NEL/UFSC, 2016. pp. 23-38.

LIMONGI, Maria Isabel. Maquiavel e Hume sobre a natureza da lei e seus fundamentos sociais. Kriterion, $\mathrm{n}^{\circ} 140,2017$. pp. 571-589.

RAWLS, John. História da Filosofia Moral. Tradução de Ana Aguiar Cotrin. São Paulo: Martins Fontes, 2005.

SCHNEEWIND, J.B. The Invention of Autonomy: a history of modern moral philosophy. Cambridge: Cambridge University Press, 1998.

WESTPHAL, Kenneth R. 'A Kantian justification of possession', in Mark Timmons (Ed.). Kant's Metaphysics of Morals: Interpretrative Essays. New York: Oxford University Press, 2002.

WESTPHAL, Kenneth R. How Hume and Kant reconstruct natural law: justifying strict objectivity without debating moral realism. New York and Oxford: Oxford University Press, 2016.

Notas

1 As citações dos textos de Tratado da Natureza Humana e Investigação sobre os Princípios da Moral serão referenciadas nas notas de rodapé indicando-se o primeiro termo que aparece no título de cada uma das obras. Em relação às citações de Tratado da Natureza Humana, o termo Tratado será seguido da numeração do Livro, Parte, Seção e Parágrafo em que a passagem ocorre, como no seguinte exemplo: Tratado, 3.2.2.10. Para as citações da obra Investigação sobre os Princípios da Moral, que estão contidas fundamentalmente no 
Apêndice 3, o termo Investigação será seguido da expressão Apêndice 3, com a posterior da indicação da numeração do parágrafo do texto, do seguinte modo: Investigação, Apêndice 3, 9. Para as duas obras, foram utilizadas as traduções publicadas pela editora da Unesp, cuja referência completa consta ao final do texto. Enfim, para as citações do Ensaio sobre a origem do governo, o termo Ensaio será seguido da paginação da edição em inglês publicada pela Oxford University Press, conforme referência completa também indicada ao final.

2Apenas para ilustrar a questão logo de início com duas passagens significativas, no Tratado Hume afirma que "não podemos considerá-la [a ideia de justiça] um princípio natural capaz de inspirar aos homens uma conduta justa para com os demais" (Tratado, 3.2.2.8), ou, ainda, que "o sentido de justiça e injustiça não deriva da natureza, surgindo antes artificialmente, embora necessariamente" (Tratado, 3.2.1.17).

3 cf. Tratado, 3.2.2.10; Investigação, Apêndice 3, 8.

4 RAWLS, John. História da Filosofia Moral. Tradução de Ana Aguiar Cotrin. São Paulo: Martins Fontes, 2005, p. 62.

5 Tratado, 3.2.2.10.

6 Tratado, 3.2.1.2.

7 LIMONGI, Maria Isabel. Hume e a Magna Carta: em torno do círculo da justiça, in Jaimir Conte; Flávio Zimmermann; Marilia Cortês de Ferraz (Org.). Ensaios sobre a filosofia de Hume. Florianópolis: NEL/UFSC, 2016, p. 24.

8 Tratado, 3.2.1.2.

9 Tratado, 3.2.1.2.

10 Tratado, 3.2.1.10.

11 Tratado, 3.2.1.11.

12 Tratado, 3.2.1.12.

13 Tratado, 3.2.1.17.

14 Tratado, 3.2.1.17.

15 No parágrafo inicial da Seção 2, Hume distingue duas questões. Por um lado, há uma questão "sobre o modo com as regras da justiça são estabelecidas pelo artificio dos homens" (Tratado, 3.2.2.1). Outro problema é investigar "as razões que nos determinam a atribuir à observância ou à desobediência dessas regras uma beleza ou deformidade morais" (Tratado, 3.2.2.1). Para colocar a última questão nos termos da formulação proposta por Schneewind, trata-se de questionar "qual papel os sentimentos morais têm ao nos motivarem a sermos justos" (SCHNEEWIND, J.B. The Invention of Autonomy: a history of modern moral philosophy. Cambridge: Cambridge University Press, 1998). Dado que o presente texto pretende compreender a distinção entre os predicados "artificial" e "natural" atribuídos a certas virtudes (especialmente à virtude da justiça), é com a primeira questão que vamos nos ocupar mais detidamente.

16 WESTPHAL, Kenneth R. How Hume and Kant reconstruct natural law: justifying strict objectivity without debating moral realism. New York and Oxford: Oxford University Press, 2016, p. 29.

17 Essa é uma boa ocasião para mencionar uma importante distinção entre virtudes naturais e artificiais que não será explorada com maior detalhe no presente texto. Virtudes naturais produzem o bem sempre, em cada ato individual de benevolência, por exemplo. Virtudes artificias como a justiça, por sua vez, extraem sua vantagem de uma espécie de acordo comum na direção da observância das regras de justiça. Segundo Hume, a mente humana possui uma "propensão para o que está contíguo" (Tratado, 3.2.7.3), para a satisfação das paixões e inclinações mais imediatas. Isso é a causa da violação de regras de justiça que torna necessária uma espécie e correção que torne "a observância das leis da justiça nosso interesse mais próximo, e sua violação, nosso interesse mais remoto" (Tratado, 3.2.7.6).

18 RAWLS, 2005, p. 69.

19 Tratado, 3.2.2.6.

20 Tratado, 3.2.2.6.

21 Tratado, 3.2.2.6.

22 Tratado, 3.2.2.8. 
23 Tratado, 3.2.2.16.

24 Tratado, 3.2.1.18.

25 Tratado, 3.2.2.9.

26 Tratado, 3.2.2.8.

27 Tratado, 3.2.2.11.

28 Tratado, 3.2.2.21.

29 cf. Tratado, 3.2.2.17.

30 Tratado, 3.2.6.9.

31 Tratado, 3.2.1.19.

32 Tratado, 3.2.1.19.

33 Tratado, 3.1.2.8.

34 Tratado, 3.1.2.8.

35 Tratado, 3.2.1.19.

36 Tratado, 3.2.2.9.

$37 \mathrm{cf}$. BUCKLE, Stephen. Natural law and the theory of property: Grotius to Hume. New York and Oxford: Oxford University Press, 1991, p. 268.

38 cf. Investigação, $A$

pêndice 3 , nota 2 .

39 cf. Investigação, Apêndice 3, 9.

40 Investigação, Apêndice 3, 9.

41 Investigação, Apêndice 3, 9.

42 Investigação, Apêndice 3, 9.

43 Investigação, Apêndice 3, 9.

44 Investigação, Apêndice 3, 9.

45 Ensaio, p. 31.

46 Ensaio, p. 28.47 Ensaio, p. 28.

38 Ensaio, p. 29.

49 WESTPHAL, 2016, p. 27.

50 A literatura secundária está longe de um consenso nesse particular. Uma interpretação que claramente afasta Hume da tradição da lei natural é oferecida por Schneewind. Segundo o autor, o único aspecto que Hume incorporou da reflexão da escola do direito natural é a crença em uma tendência para o conflito como aspecto indissociável da natureza humana (cf. SCHNEEWIND, 1998, p. 372). No mais, afirma Schneewind, Hume ampara sua reflexão na distinção entre virtudes naturais e artificiais e não faz referência a um "objetivo ou telos da natureza humana, ou [à] lei” (SCHNEEWIND, 1998, p. 368). Rawls também propõe que Hume "rejeita a doutrina do direito natural que advém do cristianismo medieval" (RAWLS, 2005, p. 66) e que encontra, na origem da moral e da justiça, leis naturais ou divinas prescritas por Deus. Limongi, por sua vez, propõe "um maquiavelismo de Hume, em seu contraste com a perspectiva da escola moderna do direito natural" (LIMONGI, 2017, p. 587). Para essa última leitura, muito resumidamente, é característico da reflexão de Hume um elemento político e social que importa do pensamento de Maquiavel uma noção de autoridade não transcendente, fundada nas relações sociais.

51 cf. BUCKLE, 1991, p. 236.

52 BUCKLE, 1991, p. 287.

52 Ibid., p. 287.

54 Ibid., p. 287.

55 WESTPHAL, 2016, p. 22.

56 WESTPHAL, 2016, p. 27.

57 Investigação, Apêndice 3, 9.

58 Tratado, 2.3.1.12.

59 Tratado, 2.3.1.8.

60 Tratado, 2.3.1.8.

61 Tratado, Introdução, 6.

62 Tratado, Introdução, 5. 
63 cf. Tratado, 2.3.3.4.

64 Tratado, 3.2.2.10.

65 cf. Tratado, 3.2.2.17.

$66 \mathrm{cf}$. Investigação, 3.1.1.

67 cf. Tratado, 3.2.6.9.

17468 CUNHA, Denise Carolina da; MACHADO, Nivaldo. Simpatia e aprovação moral da justiça na filosofia de Hume, in Jaimir Conte; Flávio Zimmermann; Marilia Cortês de Ferraz (Org.). Ensaios sobre a filosofia de Hume. Florianópolis: NEL/UFSC, 2016, p. 292.

69 Ensaio, p. 30.

70 Ensaio, p. 30

71 Ensaio, p. 30

72 Ensaio, p. 30.

73 Cf. Ensaio, p. 30.

74 HÖFFE, Otfried. 'Even a nation of demons needs the state': the dilemma of natural justice, in Howard Willians (Ed.). Essays on Kant's political philosophy. Cardif: University of Wales Press, 1992, p. 123.

75 Ibid., p. 123.

76 cf. nota 12.

77 Na Doutrina do Direito, Kant acresce à coexistência de indivíduos, inevitável em razão do formato esférico do planeta e sua extensão limitada (MS, VI, p. 311), o fato de sermos seres racionais sensiveis cujos fins são necessariamente perseguidos por meio do uso de objetos externos disponíveis na natureza (MS, VI, p. 213-214). Na esteira da leitura aqui proposta para a concepção humiana sobre a instituição de regras de justiça, Westphal propõe que, mesmo para Kant, o direito à posse de objetos externos, enquanto uma exigência imposta pela razão, é condicional. Para o intérprete, o direito de posse depende não apenas desses fatores empíricos (o que explica a exigência da Metafísica dos Costumes para derivar e justificar princípios normativos, no âmbito do Direito e da Ética, aplicáveis à condição humana), mas é condicional em outros dois sentidos: i) o uso de objetos deve ser predominantemente benigno, isto é, as regras sobre a posse e uso só fazem sentido em uma comunidade na qual os indivíduos não tenham como propósito fundamental sua mútua aniquilação, e; ii) a escassez de bens deve ser relativa, não absoluta, caso em que o uso de um objeto por um indivíduo implica a privação absoluta dos meios de sobrevivência do outro (cf. WESTPHAL, Kenneth R. 'A Kantian justification of possession', in Mark Timmons (Ed.). Kant's Metaphysics of Morals: Interpretative Essays. New York: Oxford University Press, 2002. 106-107). 